\title{
PERSPECTIVAS ACERCA DA FORMAÇÃO DE PROFESSORES NOS CURSOS DE LICENCIATURA DE UM INSTITUTO FEDERAL DO RIO GRANDE DO SUL
}

\author{
Vantoir Roberto Brancher, Naires de Cassia Nunes Moraes, Elisandra Gomes Squizani, \\ Lisiane Darlene Canterle \\ *E-mail: vantobr@yahoo.com.br \\ Programa de Pós-graduação em Educação Profissional e Tecnológica (ProfEPT) - Instituto \\ Federal Farroupilha (IFFar) - Campus Jaguari \\ DOI: 10.15628/rbept.2020.9127 \\ Artigo submetido em out/2019 e aceito em mar/2020
}

\begin{abstract}
RESUMO
O presente artigo trata do tema formação de professores em um Instituto Federal do Rio Grande do Sul, onde busca-se identificar os parâmetros legais que norteiam a formação de professores na Instituição e como esses pressupostos estão explícitos nos Projetos Pedagógicos de Cursos (PPCs) das Licenciaturas em Matemática, Química e Ciências Biológicas. Optou-se por uma pesquisa documental tendo como fonte de dados os PPCs mencionados acima, Resolução Consup no 13/2014 e o Parecer do Conselho Nacional de Educação/CP no 02/2015. Dessa maneira, percebe-se que a Instituição de ensino preocupa-se com a formação crítica e contextualizada, embasando-se também nos princípios da educação profissional e tecnológica. Entretanto, há desafios para o aperfeiçoamento dessa formação, devido à complexidade da prática educativa e à ampliação da missão docente na atualidade, requerendo não só saberes técnicos, mas uma gama de outras competências.
\end{abstract}

Palavras-Chave: Formação de professores. Licenciatura. Educação Profissional e Tecnológica.

\section{PERSPECTIVES ABOUT ON TEACHER EDUCATION IN THE UNDERGRADUATE COURSES OF A FEDERAL INSTITUTE OF RIO GRANDE DO SUL}

\begin{abstract}
The present article deals with the subject of teacher education at a Federal Institute of Rio Grande do Sul, where it is sought to identify the legal parameters that guide the teacher education in the Institution and how these assumptions are explicit in the Pedagogical Projects of Courses (PPCs) of graduation in Mathematics, Chemistry and Biological Sciences. A documentary search was chosen, the data source being the PPCs mentioned above, the Consup Resolution n. 13/2014 and the National Education Council Opinion/CP n. 02/2015. In this way, it can be seen that the Educational Institution is concerned with critical and contextualized formation, and is also based on the principles of professional and technological education. However, there are challenges for the improvement of this formation, due to the complexity of the educational practice and the expansion of the teacher's mission today, requiring not only technical knowledge, but a range of other skills.
\end{abstract}

Keywords: Teacher Education. Diploma Education. Professional and Technological Education. 


\section{INTRODUÇÃO}

O campo da formação de professores, a partir do início do século XXI, ganhou o foco das preocupações educativas. Nesse sentido, Nóvoa (2009) relata que é importante definir atributos ao "bom professor", caracterizando o trabalho docente nas sociedades contemporâneas. Na segunda metade do século XX, consolidou-se a trilogia que teve grande sucesso na caracterização do "bom professor": saber (conhecimentos), saber-fazer (capacidades) e saberser (atitudes). Já nos anos 90, o conceito de "competências" foi se impondo através das reformas educativas da época.

Emergem cada vez mais estudos sobre pluriversalidade de fatores que compõem os saberes docentes. Tardif (2014) e Nóvoa (2009) trazem essa perspectiva no intuito da valorização do sujeito docente, descrevendo o profissional como um ser em constante aprendizado e evolução. A gama de aspectos que permeiam a formação de professores refletem as exigências da sociedade atual; além disso, a dinamicidade da vida coletiva e do mundo do trabalho exige mudanças no foco da formação profissional em todas as esferas, não sendo diferente na formação de profissionais da educação.

Nesse sentido, com a implantação dos Institutos Federais (Lei $\mathrm{n}^{\circ}$ 11.892/2008), ampliou-se a preocupação sobre o aspecto da formação docente, uma vez que essas instituições assumem o compromisso com a formação de professores nas áreas com maior defasagem: Ciências e Matemática. O desafio é formar um profissional comprometido em promover a educação profissional, científica, técnica e tecnológica de qualidade através da articulação entre ensino, extensão, pesquisa aplicada e inovação para formação integral dos cidadãos (MOURA, 2015). Além disso, a relevância da multidisciplinaridade para atuação conjunta, frente ao currículo integrado, ganha amplitude visando o aspecto da interação profissional e educacional para o sucesso do ensino-aprendizagem.

Nesse sentido, o Projeto Pedagógico de Curso (PPC), no âmbito da instituição, é o instrumento que congrega a concepção do curso superior, os fundamentos da gestão acadêmica, pedagógica e administrativa e os princípios educacionais direcionados de todas as ações a serem adotadas na condução do processo de ensino-aprendizagem. Desse modo, esse documento, voltado à formação de professores, se faz importante, visto que é a base para um bom andamento do percurso acadêmico e reflete diretamente nos sujeitos, ou seja, nos futuros docentes.

Dessa forma, optou-se pela análise dos PPCs dos Cursos de Licenciatura em Matemática, Química e Ciências Biológicas. A Resolução Consup no 13/2014 define as Diretrizes Institucionais para os Cursos Superiores de Graduação de um Instituto Federal do RS e o Parecer do CNE/CP no 02/2015 institui Diretrizes Curriculares Nacionais para a Formação Inicial e Continuada dos Profissionais do Magistério da Educação Básica, com o intuito de compreender em que medida a formação de professores em um Instituto Federal do RS tem se aproximado das diretrizes gerais de formação de professores. 


\section{REFERÊNCIAL TEÓRICO}

A formação de professores e os saberes docentes tem sido objeto de estudo de pesquisadores, como Nóvoa (2009), Tardif (2014), entre outros.

Nóvoa (2009) traz cinco disposições essenciais ao ser professor na contemporaneidade, que tentam superar a dicotomia teoria/prática em tese existente e, ao mesmo tempo, romper com o modelo tecnicista de formação docente, a saber: o conhecimento, a cultura profissional, o tato pedagógico, o trabalho em equipe e o compromisso social. Nesse sentido, o conhecimento trata-se de conhecer bem aquilo que se ensina, na construção de práticas docentes que conduzam a aprendizagem do aluno; a cultura profissional que, através do diálogo e integração com outros professores, registro das práticas, reflexão sobre o trabalho e o exercício da avaliação, se chega ao aperfeiçoamento e à inovação; o tato pedagógico é a capacidade de relação e de comunicação, capaz de conquistar o aluno para o trabalho e conduzi-lo ao conhecimento; o trabalho em equipe implica em reforço das dimensões coletivas e colaborativas, intervindo conjuntamente nos projetos educativos da escola; e o compromisso social é a valorização dos princípios, dos valores, da inclusão social e da diversidade cultural.

Diante dessas dimensões essenciais ao ser professor, Tardif (2014) relata que o saber do professor é plural, composto de vários saberes de fontes variadas, que vão se complementando para a formação da personalidade e subjetividade profissional de cada indivíduo. Dessa forma, considera 0 seguinte:

[...] o saber dos professores depende, por um lado, das condições concretas nas quais o trabalho deles se realiza e, por outro, da personalidade e da experiência profissional dos próprios professores. Nessa perspectiva, o saber dos professores parece estar assentado em transações constantes entre o que eles são (incluindo as emoções, a cognição, as expectativas, a história pessoal deles, etc.) e o que fazem. O ser e o agir, ou melhor, o que Eu sou e o que Eu faço ao ensinar, devem ser vistos aqui não como dois pólos separados, mas como resultados dinâmicos das próprias transações inseridas no processo de trabalho escolar.

Os saberes de um professor são uma realidade social materializada através de uma formação, de programas, de práticas coletivas, de disciplinas escolares, de uma pedagogia institucionalizada, etc., e são também, ao mesmo tempo, os saberes dele (TARDIF, 2014, p. 16).

Além disso, é evidente que o saber-fazer também tem origem social, confluindo de vários saberes, como: da família do professor, da escola que o formou e de sua cultura pessoal; das universidades ou das escolas normais; da instituição (programas, regras, princípios pedagógicos, objetivos, finalidades, etc.); dos pares, dos cursos de reciclagem, etc. (TARDIF, 2014). Dessa maneira, aprende-se a dominar progressivamente os saberes necessários à realização do trabalho docente e, nesse fazer, Tardif (2014) considera a 
importância do saber herdado da experiência escolar anterior, sendo muito forte, visto que, mesmo com a formação universitária, esses saberes persistem.

Nesse contexto, os saberes dos docentes são temporais, supondo que ensinar supõe aprender a ensinar, assim:

[...] os saberes oriundos da experiência de trabalho cotidiana parecem constituir 0 alicerce da prática e da competência profissionais, pois essa experiência é, para o professor, a condição para a aquisição e produção de seus próprios saberes profissionais. Ensinar é mobilizar uma ampla variedade de saberes, reutilizando-os no trabalho para adaptá-los e transformá-los pelo e para o trabalho. A experiência de trabalho, portanto, é apenas um espaço onde o professor aplica saberes, sendo ela mesma saber do trabalho sobre saberes, em suma: reflexividade, retomada, reprodução, reiteração daquilo que se sabe naquilo que se sabe fazer, a fim de produzir sua própria prática profissional (TARDIF, 2014, p. 21).

Diante do apresentado, é significativo destacar sobre a formação de professores para a Educação Profissional e Tecnológica (EPT). Moura (2015) demonstra claramente 0 quanto as questões econômicas interferem na sociedade, na educação e trabalho. A era da globalização, marcada pelos avanços tecnológicos, agrava as desigualdades sociais, potencializando a demanda por mão de obra barata, gerando um processo de desumanização. Assim, espera-se que a educação contribua para a construção gradativa de uma sociedade mais justa, coerentemente com a perspectiva de desenvolvimento socioeconômico.

A busca por uma sociedade mais inclusiva é um dos desafios da educação, de forma que o sujeito construa sua identidade social e política, sua autonomia, autorrealização, emancipação e criticidade. Além disso, que busque a transformação, melhorias coletivas para uma sociedade mais justa e igualitária. Os docentes necessitam ter uma formação voltada para a valorização do ser humano, em contraponto ao modelo de desenvolvimento socioeconômico vigente. Também, rever seu papel para assumir uma atitude problematizadora e mediadora do processo ensino-aprendizagem, tendo a perspectiva de que o estudante é o agente desse processo. Obviamente, a formação didático-político-pedagógica é essencial, visando a aproximação das relações entre educação e trabalho e do campo da educação profissional, dessa forma, delineiam-se os cursos de licenciatura, pós graduação lato e scricto sensu voltados para a área (MOURA, 2015).

A formação docente necessita, igualmente, da concepção de que a pesquisa e o avanço tecnológico devem estar voltados para o desenvolvimento de bens e serviços a fim de melhorar as condições de vida dos coletivos sociais, uma vez que:

[...] a unidade ensino-pesquisa colabora para edificar a autonomia dos indivíduos porque é através do desenvolvimento da capacidade de aprender a aprender, proporcionado pela investigação, pela inquietude e pela responsabilidade social, que o estudante deixa de ser um depósito de conhecimentos produzidos por uns (especialistas) 
e transmitidos por outros (geralmente os professores) e passa a construir, desconstruir e reconstruir suas próprias convicções a respeito da ciência, da tecnologia, do mundo e da própria vida (MOURA, 2015, p. 36).

E não, apenas, para produzir bens de consumo que fortalecem 0 mercado e, consequentemente, aumentam as desigualdades sociais.

Sobre a materialização da formação do professor, Nóvoa (2009), em um primeiro momento, sugere que o profissional participe do seu processo formativo bem como de seus próprios colegas, como condição de uma práxis que deve ser referência para o trabalho docente nas escolas, possibilitando, com isso, uma atitude mais reflexiva de todos esses sujeitos. Outro aspecto a ser considerado é a necessidade de promover novos modos de organização da profissão, na concepção de oportunizar o pertencimento e a identidade profissional docente. A partir disso, sabe-se que os normativos legais que regem as instituições escolares estão cada vez mais burocratizados, marcados por tradições individualistas ou por rígidas regulações externas que, desse modo, prejudicam a autonomia docente. Ainda, conforme Nóvoa (2009), é indispensável reforçar a dimensão pessoal e a presença pública do professor, captando o sentido da profissão; construindo, assim, um percurso de aprendizagem significativa ao longo da vida, sempre buscando valorizar e ampliar a visibilidade pública da profissão.

Nesse sentido, a construção do "ser professor" se dá a partir de sua formação inicial que precisa contribuir para que este possa atuar nas mais diversas modalidades de ensino, propondo diferentes metodologias para possibilitar um processo de ensino-aprendizagem coerente com a realidade dos sujeitos envolvidos. No entanto, ainda há muito que avançar para romper com uma formação fragmentada que persiste nos cursos de formação de professores. É preciso apontar estratégias para uma formação ampla e integral, onde o professor se constitua enquanto tal e entenda-se em processo de formação permanente, dotados de vivências que promovam seu desenvolvimento profissional. Das licenciaturas, nas universidades, espera-se que deem conta dessa formação, uma vez que o foco está na formação específica da área e não em uma formação integral em que o futuro professor possa vislumbrar os conceitos específicos em diversas situações de ensino, sem separação entre conhecimentos específicos e pedagógicos (MALDANER, 2013).

Assim sendo, é necessário que a formação inicial de professores esteja em sintonia com as exigências da ressignificação curricular e da formação integral. Principalmente em instituições que assumem legalmente 0 compromisso social e político de emancipação do cidadão, como é o caso dos Institutos Federais de Educação, Ciência e Tecnologia. Esses dedicam, pelo menos, $20 \%$ de suas vagas a cursos de licenciatura, sobretudo nas áreas de ciências e matemática. Esses cursos preveem legalmente a formação de pessoal ético e comprometido com a indissociabilidade entre educação e prática social, capazes de levar em consideração a historicidade dos conhecimentos e dos sujeitos da aprendizagem. Que sejam capazes de diversificar suas práticas profissionais, fazendo da contextualização, 
interdisciplinaridade e flexibilização curricular ferramentas favoráveis à compreensão de significados e à interação entre os saberes escolares e às vivências dos educandos (BRASIL, 2012.

Diante disso, as pesquisas relacionadas à formação de professores têm sido cruciais, buscando apontar elementos que promovam o desenvolvimento profissional docente, tanto na formação inicial quanto ao longo de sua atividade docente. Formação essa que possibilite ao professor condições de atender às especificidades da EPT, ou seja, "um currículo integrado à vida dos educandos, à dinâmica da interação e dos processos históricos, sociais, econômicos e culturais relevantes que eles vivenciam" (MACHADO, 2010, p. 82), voltado para a concepção de diferentes maneiras de se organizar o processo de ensinoaprendizagem.

Os cursos de formação de professores devem possibilitar, aos futuros docentes, acesso a diferentes metodologias de ensino para oferecer uma aprendizagem significativa a seus alunos, uma vez que:

[...] compreende-se que uma prática pedagógica significativa decorre da necessidade de uma reflexão sobre o mundo do trabalho, da cultura desse trabalho, das correlações das forças existentes, dos saberes construídos a partir do trabalho e das relações sociais que se estabelecem na produção (MOURA, 2007, p. 22).

Dessa maneira, os cursos de licenciatura de um Instituto Federal, instituição que promove a educação profissional e tecnológica sob a perspectiva de um currículo integrado, precisam preparar os professores para atuar nesta modalidade, além da educação básica, uma vez que "é preciso reconhecer que a docência na EPT é muito mais que mera transmissão de conhecimentos empíricos ou processo de ensino de conteúdos fragmentados e esvaziados teoricamente" (MALDANER, 2017, p. 191). Pensar a formação de professores para a EPT:

[...] para além da formação técnica no sentido do domínio de conteúdos específicos e formação específica (pedagógica) para se tornar professor, pressupõe um compromisso político para com a classe que vive do próprio trabalho, a classe trabalhadora (MALDANER, 2017, p. 183).

Assim, busca-se formar não apenas técnicos, mas pessoas que, ao atuarem como profissionais, possam compreender a realidade e intervir no meio em que estão inseridos, uma vez que as concepções do sujeito é que direcionam suas ações.

Para isso, é indispensável que "a integração entre conhecimentos gerais e específicos seja construída continuamente ao longo da formação, sob os eixos do trabalho, da ciência e da cultura" (RAMOS, 2012, p. 122). Preparando, então, profissionais para o mundo do trabalho, que possam dominar as técnicas e tecnologias para desvendar os problemas oriundos de sua formação e da comunidade em que estão inseridos. 
Os institutos federais trazem em sua lei de criação o compromisso com a formação de professores. No artigo $7^{\circ}$, menciona-se que um dos objetivos dos Institutos Federais é ofertar "cursos de licenciatura, bem como programas especiais de formação pedagógica, com vistas na formação de professores para a educação básica, sobretudo nas áreas de ciências e matemática, e para a educação profissional" e ainda, "ministrar cursos de formação inicial e continuada de trabalhadores, objetivando a capacitação, o aperfeiçoamento, a especialização e a atualização de profissionais [...]" (BRASIL, 2008), criando espaços de geração de conhecimento a partir daqueles previamente trazidos pelos envolvidos. Baseado nesse pressuposto, os Projetos Pedagógicos de Curso são construídos com base no Parecer CNE/CP no 02/2015, que institui diretrizes curriculares nacionais para a formação inicial e continuada dos profissionais do magistério da educação básica, e na Resolução Consup no 13/2014, que define diretrizes institucionais gerais e diretrizes curriculares institucionais da organização didático-pedagógico para os cursos superiores de graduação do Instituto Federal Farroupilha.

\section{METODOLOGIA}

Tendo em vista os objetivos deste estudo, optou-se por adotar a análise documental como aporte metodológico. A fim de determinar quais seriam as fontes de dados, considerou-se que, conforme Marconi e Lakatos (2010), os documentos oficiais constituem geralmente a fonte mais fidedigna de dados $\mathrm{e}$ podem dizer respeito à atos individuais ou coletivos, de alcance local ou nacional, relacionados à vida social ou política. Por isso, as fontes de dados são os Projetos Políticos Pedagógicos dos Cursos de Licenciatura em Matemática, Química e Ciências Biológicas de um Instituto Federal do RS, a Resolução Consup no 13/2014, que define Diretrizes Institucionais Gerais e Diretrizes Curriculares Institucionais Didático-Pedagógica para os Cursos Superiores de Graduação deste Instituto, e o Parecer do Conselho Nacional de Educação nำ02/2015, que institui as Diretrizes Nacionais para Formação Inicial e Continuada dos Profissionais do Magistério da Educação Básica.

A escolha se deu pelo fato de que este método pode configurar-se como importante técnica de abordagem de dados qualitativos, podendo constituir-se em complemento a informaçõe ou mesmo desvelando aspectos novos de um problema (LUDKE; ANDRÉ, 1986). Além disso, a análise de documentos não é apenas uma fonte de informações sobre determinado contexto, mas os documentos também constituem uma poderosa fonte de onde brotam evidências que justificam e fundamentam problemáticas e ações.

Inicialmente, realizou-se a leitura e o fichamento dos documentos da Resolução Consup no 13/2014 e do Parecer do Conselho Nacional de Educação no 02/2015, buscando elementos que contribuam para a qualificação da formação de professores. Com isso, visando a: integração dos conhecimentos específicos e pedagógicos; superação da dicotomia existente entre teoria e prática; diversificação metodológica através da contextualização, interdisciplinaridade e flexibilização curricular; e uma formação comprometida com um projeto de sociedade democrática e igualitária. 
Após, passou-se à análise dos PPCs dos cursos já mencionados. Para isso, realizou-se a leitura e o fichamento desses documentos tendo como embasamento os aspectos identificados na análise da Resolução Consup nº 13/2014 e do Parecer do Conselho Nacional de Educação no 02/2015. Desse modo, foi estabelecido um elo comparativo entre os documentos, sendo possível identificar suas proximidades, semelhanças e as dimensões que podem ser qualificadas na elaboração dos PPCs.

\section{RESULTADOS E DISCUSSÕES}

Os parâmetros legais, que norteiam a formação de professores em institutos federais do Rio Grande do Sul, foram analisados em busca dos elementos que balizam a Educação Profissional e Tecnológica, a saber: trabalho, ciência, tecnologia, cultura, currículo integrado, interdisciplinaridade e contextualização, para verificar como estes estão explícitos nos PPCs dos cursos de Licenciatura em Ciências Biológicas, Matemática e Química.

O Parecer CNE/CP n- 02/2015, em seu texto, deixa clara a íntima relação necessária entre a teoria e a prática na formação de professores, contemplando a indissociabilidade entre ensino, pesquisa e extensão. A partir dessa concepção, são traçados alguns nortes para a formação de profissionais do magistério, delineando alguns princípios fundamentais e reforçando a relação entre os conhecimentos teóricos e a prática (práxis). Deixando claro, também, que o pilar fundamental para a constituição da práxis docente deve estar solidamente fundada em conhecimentos específicos e didáticopedagógicos.

Assim sendo, o documento reitera diversas vezes, em seu texto, a indicação de que a formação de professores deve estar intimamente ligada ao contexto social no qual se insere. Em sua constituição e implementação, os cursos de formação de profissionais do magistério da educação básica devem considerar as particularidades e necessidades locais, promovendo a integração entre a formação inicial e continuada através do ensino, da pesquisa e da extensão (BRASIL, 2015).

Quanto ao repertório de conhecimentos que o egresso deve possuir, o documento deixa claro que este deve ser pautado pela interdisciplinaridade, contextualização, democratização, dentre outros princípios que o permitam exercer sua atividade profissional de forma ética e comprometida com a emancipação do sujeito e da sociedade.

Para isso, em seu Capítulo IV, são definidos os núcleos nos quais se constituem os cursos de formação de professores. São eles: I - estudos e formação geral; II - aprofundamento e diversificação de estudos nas áreas de atuação; III - Estudos integradores. Resumidamente, o núcleo I corresponde aos conhecimentos específicos e pedagógicos, que abrangem os princípios de justiça social, cidadania, interdisciplinaridade, relação entre educação e trabalho, articulação entre teoria e prática e pesquisa como princípio educativo (BRASIL, 2015). 
O núcleo II se refere aos aspectos da atividade docente além da sala de aula, ou seja: gestão, criação de materiais didáticos, pesquisa e aplicação dos conhecimentos pedagógicos, teorias da educação, legislação, políticas e avaliação. Por fim, o terceiro núcleo se refere à complementaridade da formação através da participação em seminários, intercâmbios e atividades práticas em consonância com as particularidades do contexto em que a atividade docente se insere. Mais uma vez, fica claro que tal projeto deve ser elaborado em regime de colaboração e integração com os sistemas locais de ensino.

A Resolução Consup no 13/2014 traz alguns pressupostos para a construção das diretrizes institucionais gerais e diretrizes curriculares institucionais da organização didático-pedagógico para os cursos superiores de graduação do Instituto Federal Farroupilha, nos graus de licenciatura, bacharelado e tecnologia. O texto traz algumas considerações que embasam os 214 artigos, sendo que, em relação aos pressupostos da EPT, considera ações que articulem os conhecimentos à vida dos estudantes, seus contextos e realidades a fim de atender suas necessidades e expectativas. Além disso, considera as dimensões do trabalho, da ciência, da tecnologia e da cultura como eixos integradores entre os diferentes conhecimentos, a saber: o trabalho como princípio educativo, a pesquisa como princípio pedagógico, os direitos humanos como princípio norteador e a sustentabilidade socioambiental como meta universal.

Em relação à Licenciatura, objeto deste estudo, a resolução conceitua como curso superior aquele que confere ao diplomado competências para atuar como professor na educação básica, com o grau de licenciado. De acordo com a Lei $\mathrm{n}^{0}$ 11.892/2008, os institutos federais devem reservar, no mínimo, $20 \%$ de suas vagas para cursos de Licenciatura e a programas especiais de formação pedagógica, visando a formação de professores para educação básica, especialmente na área de ciências e matemática. $E$, também, para a educação profissional, sendo este um dos objetivos da Educação Superior do instituto federal, juntamente com a prioridade à formação integral aliada à formação profissional nos campos tecnológicos e da educação. Além disso, a Resolução prevê a organização do Comitê Gestor Institucional de Formação Inicial e Continuada de Profissionais do Magistério da Educação Básica (COMFOR) que, entre outras atribuições, compete "assegurar a indução, a articulação, a coordenação e a organização de programas e ações de formação inicial e continuada de profissionais do magistério da educação básica" (art. 16) (BRASIL, 2014).

O Título IV da Resolução trata especificamente dos cursos superiores de licenciatura do Instituto Federal, enfatizando que a formação no âmbitos dos cursos "deve ocorrer a partir de sólida formação teórica e prática, integrando as dimensões específicas e pedagógicas do currículo, visando uma formação voltada à atuação na educação básica e educação profissional técnica de nível médio e para o prosseguimento dos estudos" (art. 112) (BRASIL, 2014). Esta integração é possibilitada na prática enquanto Componente Curricular (doravante $\mathrm{PeCC}$ ) que é um espaço de "criação e reflexão acerca do trabalho docente e do contexto social em que se insere, com vistas à integração entre a formação e o exercício do trabalho docente" (art. 120) (BRASIL, 2014). Além de colaborar com a formação integral do licenciando, as atividades da PeCC se 
configuram espaços que oferecem outras condições para a ocorrência de "[...] aprendizagens em relação ao constituir-se professor, permitindo construir conhecimento profissional fundamentado, entender-se em processo de formação permanente" (GALIAZZI, 2003, p. 223).

Os PPCs trazem os objetivos gerais dos cursos de Licenciatura do Instituto Federal escolhido para análise, sendo que, para a Licenciatura em Matemática, tem-se:

formar profissionais qualificados capazes de atuar na Educação Básica e em outros espaços educativos, formais ou informais, bem como de prosseguirem seus estudos na pós-graduação, possibilitando a formação de cidadãos com embasamento teóricometodológico e de futuros professores com capacidade de posicionarem-se de maneira crítica, criativa, responsável, construtiva e autônoma no processo escolar e social (BRASIL, 2016b, p. 9).

Em relação à Licenciatura em Química:

Oferecer aos Licenciados em Química ampla formação teórica e prática, integrando as dimensões específicas e pedagógicas da atuação docente, voltada para educação básica (ensino fundamentalanos finais- e ensino médio) e educação profissional e tecnológica (BRASIL, 2016c, p. 16).

Para a Licenciatura em Ciências Biológicas:

O Curso superior de Licenciatura em Ciências Biológicas visa formar profissionais dotados de ampla perspectiva cultural, científica e tecnologicamente competentes, aptos a interpretar e responder às questões colocadas pelo meio social. Pretende ainda favorecer 0 desenvolvimento das ciências biológicas pelo fortalecimento do ensino, do estímulo à investigação científica e à extensão e à preservação e difusão dos bens culturais, buscando a promoção do indivíduo e da sociedade (BRASIL, 2016a, p. 16).

Nesse contexto, um dos motivos pelos quais se optou por oferecer os Cursos Superiores de Licenciatura em Matemática, Química e Ciências Biológicas na cidade em que este Instituto está localizado é o de que não há profissionais suficientes com tal qualificação para atender à demanda da rede pública e privada do município e região. Tanto em seus objetivos quanto nas justificativas para a oferta dos cursos, percebe-se a preocupação em atender as necessidades da comunidade local, o que é reiterado veementemente no Parecer nº 02/2015 do Conselho Nacional de Educação e igualmente orientado na Resolução Consup nำ13/2014.

Com relação ao currículo formativo, os PPCs preveem componentes curriculares que proporcionam ao acadêmico inserir-se na prática docente, construindo sua identidade profissional e conhecendo a realidade do contexto escolar da sua comunidade. Além disso, o currículo está organizado a partir de 
três núcleos de formação: Núcleo Comum, Núcleo Específico e Núcleo Complementar. Essa organização remete imediatamente ao exposto pelo Parecer no 02/2015 do Conselho Nacional da Educação que orienta a organização dos núcleos sobre os quais a formação dos professores deve se apoiar, são eles: I - estudos e formação geral; II - aprofundamento e diversificação de estudos nas áreas de atuação; III - Estudos integradores.

No Projeto Pedagógico dos três cursos, fica claro a que se refere cada um destes, sendo que o primeiro (Núcleo Comum) contempla os conhecimentos comuns à formação de professores, independente da sua área de formação. Para dar conta desses conhecimentos, o Núcleo Comum se subdivide em dois: Núcleo Básico, que trata dos conhecimentos básicos da área, visando atender às necessidades de nivelamento do acadêmico na área, para seu avanço no curso; e Núcleo Pedagógico, que se refere aos estudos concernentes aos conhecimentos relativos ao campo da educação com vistas à compreensão dos fundamentos teóricos, políticos e históricos da educação.

O Núcleo Específico, como o seu próprio nome indica, trata dos conhecimentos específicos de cada área, incluindo a transposição didática dos conteúdos na perspectiva da atuação docente nesse campo (BRASIL, 2014). Já o Núcleo complementar, assim como citado no Parecer no 02/2015 do CNE, se refere a atividades acadêmico-científico-culturais, incluindo disciplinas eletivas que visam atualização constante da formação do professor.

Tais núcleos em que se fundam os Cursos de Licenciatura deste Instituto são articulados e desenvolvidos durante todo o percurso formativo pela prática enquanto Componente Curricular ( $\mathrm{PeCC}$ ). Conforme, por exemplo, o PPC da Licenciatura em Matemática:

\begin{abstract}
As disciplinas de Prática enquanto Componente Curricular (PeCC) perpassam todo o currículo do curso desde o primeiro até o último semestre. As ementas destas disciplinas, assim como a sequência conceitual adotada, permitem além da articulação e a interlocução entre as disciplinas dos diferentes núcleos, a interdisciplinaridade assegurada por meio de normativa interna do Instituto que prevê o desenvolvimento das disciplinas do PPC de forma colaborativa entre os professores através de um projeto interdisciplinar a ser elaborado no início de cada período letivo pelo colegiado do Curso com diferentes estratégias didáticas que viabilizem o desenvolvimento do mesmo (BRASIL, 2016b, p. 24).
\end{abstract}

Frente a isso, entende-se que a PeCC consolida-se ao passo que os acadêmicos tomam posse dos diferentes campos dos saberes docentes e articulam-os através da práxis docente, conforme exposto nos documentos analisados. Além disso, a interlocução dos diferentes núcleos na formação de professores cria possibilidades de contato, análise e reflexão do contexto educacional no qual o Instituto Federal está inserido. Dessa forma, os profissionais em formação passam por um processo de tomada de consciência de seu papel social enquanto educadores, ampliando sua visão a respeito da contribuição da aprendizagem científica na formação dos indivíduos para 0 exercício da cidadania. Mais uma vez, percebe-se a proximidade conceitual e 
atitudinal dos PPCs hora analisados com o parecer do Conselho Nacional da Educação nº 02/2015 e com a Resolução Consup nํ13/2014.

Em relação aos pressupostos da EPT - trabalho, ciência, tecnologia, cultura, interdisciplinaridade e contextualização - mencionados na Resolução Consup n 13/2014 como eixos integradores entre os conhecimentos de distintas naturezas, os três PPCs analisados apresentam claramente que o currículo:

[...] segue os princípios da estética, da sensibilidade, da política, da igualdade, da ética, da identidade, da interdisciplinaridade, da contextualização, da flexibilidade e da educação como processo de formação na vida e para a vida. Sustenta-se por uma concepção de sociedade, trabalho, cultura, ciência, tecnologia e ser humano (BRASIL, 2016c, p. 16).

Conforme o exposto, percebe-se com clareza que a formação integral perpassa todo o percurso formativo dos licenciados e os PPCs estão coerentes com os documentos analisados; muito embora tenham sido elaborados com base no Parecer no 02/2002 que serviu como base para a estruturação do texto do Parecer no 02/2015.

\section{CONSIDERAÇÕES FINAIS}

Por fim, é possível perceber a necessidade de se buscar alternativas para a formação de professores que deem conta das exigências dos sistemas educativos e das expectativas do profissional em formação, em uma perspectiva que considere a atividade docente ao longo dos anos de serviço. Formação, essa, que promova ao professor o desejo de continuar buscando atualização ao longo de seu exercício profissional, inclusive participando como pesquisador de sua área de atuação.

Destarte, compreende-se a ação docente, não só como técnica, mas também como um reflexo do professor, das construções na relação com outros sujeitos, percebendo-se que 0 ato de ensinar e aprender é dinâmico e evolui na práxis cotidiana, tendo um enfoque crítico e reflexivo (MOREIRA et al., 2006).

Considerando a diversidade de fatores que produzem a formação e os saberes docentes no contexto educacional atual, o Instituto Federal, objeto desta análise, preocupa-se com a formação crítica e contextualizada, embasando-se também nos princípios da educação profissional e tecnológica. Não obstante, devido à complexidade da prática educativa, ainda revela-se um desafio aperfeiçoar esta formação, dado que a profissão requer não só saberes técnicos, mas uma gama de outras competências. 


\section{REFERÊNCIAS}

BRASIL. Lei no 11.892, de 29 de dezembro de 2008. Institui a Rede Federal de Educação Profissional, Científica e Tecnológica, cria os Institutos Federais de Educação, Ciência e Tecnologia, e dá outras providências. Diário Oficial da União: seção 1, Brasília, DF, p. 1, 30 dez. 2008. PL 3775/2008. Disponível em: http://www.planalto.gov.br/ccivil_03/_ato2007-2010/2008/lei//11892.htm.

Acesso em: 17 nov. 2018.

BRASIL. Ministério da Educação. Instituto Federal de Educação, Ciência e Tecnologia Farroupilha, Campus Alegrete. Projeto Pedagógico do Curso de Licenciatura em Ciências Biológicas. Brasília: MEC, 2016a. Disponível em: https://www.iffarroupilha.edu.br/projeto-pedag\%C3\%B3gico-de-curso/campusalegrete. Acesso em: 23 nov. 2018.

BRASIL. Ministério da Educação. Instituto Federal de Educação, Ciência e Tecnologia Farroupilha, Campus Alegrete. Projeto Político Pedagógico do Curso Superior de Licenciatura em Matemática. Brasília: MEC, 2016b. Disponível em: https://www.iffarroupilha.edu.br/projeto-pedag\%C3\%B3gico-decurso/campus-alegrete. Acesso em: 23 nov. 2018.

BRASIL. Ministério da Educação. Instituto Federal de Educação, Ciência e Tecnologia Farroupilha, Campus Alegrete. Projeto Pedagógico do Curso de Licenciatura em Química. Brasília: MEC, 2016c. Disponível em: https://www.iffarroupilha.edu.br/projeto-pedag\%C3\%B3gico-de-curso/campusalegrete. Acesso em: 23 nov. 2018.

BRASIL. Ministério da Educação. Parecer no 02/2015, de 9 de junho de 2015. Diretrizes Curriculares Nacionais para a Formação Inicial e Continuada dos Profissionais do Magistério da Educação Básica. Brasília: CNE/CP, 2015. Disponível em: http://portal.mec.gov.br/publicacoes-para-professores/30000uncategorised/21123-2015-pareceres-do-conselho-pleno. Acesso em: 01 nov. 2018.

BRASIL. Ministério da Educação. Resolução no 2/2002, de 19 de fevereiro de 2002. Institui a duração e a carga horária dos cursos de licenciatura, de graduação plena, de formação de professores da Educação Básica em nível superior. Brasília: CNE/CP, $2002 . \quad$ Disponível em: http://portal.mec.gov.br/cne/arquivos/pdf/CP022002.pdf. Acesso em: 01 nov. 2018.

BRASIL. Ministério da Educação. Resolução no 6/2012, de 20 de setembro de 2012. Define Diretrizes Curriculares Nacionais para a Educação Profissional Técnica de Nível Médio. Brasília: CNE/CEB, 2012. Disponível em: http://portal.mec.gov.br/index.php?option=com_docman\&view=download\&alias $=11663$-rceb006-12-pdf\&category_slug=setembro-2012-pdf\&ltemid=30192.

Acesso em: 18 abr. 2018. 
BRASIL. Ministério da Educação. Resolução no 13/2014, de 28 de maio de 2014. Define Diretrizes Institucionais Gerais e Diretrizes Curriculares Institucionais da Organização Didático Pedagógica para os Cursos Superiores de Graduação do Instituto Federal Farroupilha e dá outras providências. Santa Maria: SEPT/CONSUP, 2014. Disponível em: https://www.iffarroupilha.edu.br/regulamentos-elegisla\%C3\%A7\%C3\%B5es/resolu\%C3\%A7\%C3\%B5es/item/1343resolu\%C3\%A7\%C3\%A3o-consup-n\%C2\%BA-13-2014-diretrizesinstitucionais-para-os-cursos-superiores-de-gradua\%C3\%A7\%C3\%A3o. Acesso em: 01 nov. 2018.

GALIAZZI, Maria do Carmo. As aprendizagens dos alunos. In: GALIAZZI, Maria do Carmo. Educar pela pesquisa: ambiente de formação de professores de ciências. ljuí: Ed. Unijuí, 2003. p. 223-259.

LUDKE, Menga; ANDRÉ, Marli Eliza D. A. Pesquisa em educação: abordagens qualitativas. São Paulo: EPU, 1986.

MACHADO, Lucília. Ensino Médio e técnico com currículos integrados: propostas de ação didática para uma relação não fantasiosa. In: MOOL, Jaqueline et al. (Org.). Educação profissional e tecnológica no Brasil contemporâneo: desafios, tensões e possibilidades. Porto Alegre: Artmed, 2010. p. 80-95.

MALDANER, Jair José. A formação docente para Educação Profissional e Tecnológica: breve caracterização do debate. Revista Brasileira da Educação Profissional e Tecnológica, [S. I.], v. 2, n. 13, p. 182-195, dez. 2017. Disponível em: http://www2.ifrn.edu.br/ojs/index.php/RBEPT/article/view/5811. Acesso em: 29 out. 2018.

MALDANER, Otávio Aloisio. Conhecimento peculiar do professor. In: MALDANER, Otávio Aloisio. A formação inicial e continuada de professores de química: professores/pesquisadores. 4. ed. ljuí: Ed. Unijuí, 2013. p. 43-49.

MARCONI, Marina de Andrade; LAKATOS, Eva Maria. Fundamentos da metodologia científica. São Paulo: Atlas, 2010.

MOREIRA, Jacqueline Poersch et al. O professor como cuidador. Revista Bioética, Brasília, v. 14. n. 2, p. 163-169, 2006.

MOURA, Dante Henrique. A formação de docentes para a educação profissional e tecnológica. Revista Brasileira da Educação Profissional e Tecnológica, [S. I.], v. 1, n. 1, p. 23-38, jul. 2015. Disponível em: http://www2.ifrn.edu.br/ojs/index.php/RBEPT/article/view/2863/1004. Acesso em: 29 out. 2018.

MOURA, Dante Henrique. Educação básica e educação profissional e tecnológica: dualidade histórica e perspectivas de integração. Revista Holos, Natal, v. 2, n. 23, p. 4-30, 2007. Disponível em: 
<http://www2.ifrn.edu.br/ojs/index.php/HOLOS/article/viewFile/11/110> Acesso em: 17 nov. 2018.

NÓVOA, Antonio. Professores: imagens do futuro presente. Lisboa: EDUCA, 2009.

RAMOS, Marise. Possibilidades e desafios na organização do currículo integrado. In: FRIGOTTO, Gaudêncio; CIAVATTA, Maria; RAMOS, Marise. (org). Ensino Médio Integrado: concepção e contradições. 3. ed. São Paulo: Cortez, 2012. p. 107-128.

TARDIF, Maurice. Saberes docentes e formação profissional. 17. ed. Petrópolis: Vozes, 2014. 